\title{
Editorial
}

Why educational research should remain mindful of its position: Questions of boundaries, identity and scale.

\section{Emma Wainwright}

David Aldridge

\section{Gert Biesta}

\section{Ourania Filippakou}

We are now half way through our four-year editorship of BERJ and in this, our third, editorial we offer midway reflections on the past two years, as well as look ahead to what BERJ will, and looks to, publish. Pulling through key ideas from our previous editorials, we consider the trajectory of the journal through the themes of boundaries, identity and scale as a means of offering points for wider discussion on educational research and its position. In so doing, we invite authors to submit manuscripts that engage explicitly with issues relating to these themes.

In our first 'vision-setting' editorial, 'Why the nature of educational research should remain contested' (Aldridge et al. 2018), we appraised the field of education and offered a set of questions which included: What counts as educational research? Is there a 'gold standard'? Who is best placed or best qualified to carry out educational research? In flagging these, we emphasised an approach to educational research that we intended to be broad and inclusive, and which has informed our editorial decisions over the past two years. We called for research which was a reflection on as well as of the field of education, suggesting that the nature of educational research must remain contested. We have also been keen to encourage educational research that raises new and even uncomfortable questions, and finds new areas of and for research. In so doing, as well as seeking to solve questions and respond to policy imperatives which often pose issues and steer research, we want educational research to identify and cause problems too, as we stressed in our 2019 editorial (Biesta et al, 2019).

It is from this perspective and with this vision that from this 2020 BERJ volume we are introducing special issues and sections as a mechanism through which to open up and further develop debate on critical and complex issues in and for educational research. This is not a change of direction for BERJ but rather a consolidation and re-emphasis of the journal's role and place in not just following research agendas but setting them as well. With this in mind, we use this editorial as a moment to reflect back and think ahead to further consider what we research (and by implication, how we research), what is published in this journal's pages, the legitimisation of topics for wider debate and, more broadly, the shaping of an educational research agenda.

\section{i. Boundaries}

Whether education is an identifiable subject area and discipline in its own right, whether it is inextricably tied to the 'core' disciplines of sociology, psychology, history and philosophy, whether we can think of it in relation to newer subject ties, or whether it is best understood on more inter-, trans- and cross-disciplinary terms, are all rightly and readily debated, and important for education's vibrancy and future. While BERA openly strives to be inclusive of the diversity of educational research and scholarship, and its establishment was motivated, in part, 
by the 'allure of interdisciplinarity' (McCulloch, 2012: 296), other countries, regions and linguistic communities, position education in rather different ways (Biesta et al, 2014).

The history of education and this presumption of interdisciplinarity, at some level and in some ways, sets it apart from and at an advantage to many other subject areas. Its boundaries must then, self-evidently, be porous and malleable, and the field open to collaborations, new perspectives and directions. But while the push for interdisciplinarity can be positive and productive, this can lead to concerns about a clear disciplinary foundation (Whitty and Furlong, 2017), making it more vulnerable than fields with a strong discipline-based identity (see for example Tibble, 1966). This is a point of tension that continues to be debated in this and other journals (Lawn and Furlong, 2007; 2009).

Disciplinary cultures often work to harmonise and integrate while simultaneously police the boundaries of a discipline. They are inherently bound up with power relations and struggles to assert and position a discipline, highlighting disciplinary role and importance. Such cultures define who has the authority to speak, about which factors and subjects, and through which processes and means. They stake out a territory and then guard and defend that through boundary work (Gieryn, 1999). Education is no different in this respect, not just because it is interested in its own position, but also because of the historic ambition of educational research to contribute to the improvement of educational practice.

While education has vibrant sub- and contributing disciplines, with their own protected spaces of debate, knowledge generation and dissemination, generalist journals such as BERJ remain critical for mapping the terrain of the field more broadly and, in so doing, being at the forefront of pushing and extending its boundaries. This encourages us to think about what research can achieve, what is possible through research and extending possibilities in terms of subject matter, as well as changing perceptions of what is worthy of research and asking questions about what is valuable and worthwhile in education. We need to consider different boundary types: temporal boundaries - that include historical reflections, contemporaneous considerations and future predictions; spatial boundaries - that recognise that education works in and through many forms, settings and relationships; and, theoretical, conceptual and methodological boundaries that challenge and encourage us to view things in new and sometimes unsettling ways.

In this respect, our own role as editors involves boundary work and we need to be alert to uncritically reinforcing and safeguarding boundaries. Journal editing is in many ways a gatekeeping activity which draws and then polices these boundaries, while simultaneously encouraging some boundary-crossing initiatives and activities. We should be wary of normalising visions of a field that keep boundaries in place and in check. These are challenges for a journal such as BERJ but necessary for an outward looking field that is attentive to developments within and beyond education and is aimed at stimulating and expanding debate. We are keen to receive manuscripts that probe these issues in more depth, both from 'within' and 'outside' the British context.

\section{ii. Identity}

These considerations of boundaries, their erosion, change and crossing, are tied closely to questions about the identity of education and those that are a part of it - whether as students, researchers, policy makers or practitioners. Within a subject area as diverse as education sits a range of identities in terms of institutional, organisational and disciplinary location. The diversity of readers and authors of BERJ is a marker of its strength and status as a generalist journal, and 
is central to its ethos of publishing on the widest range of educational topics. Nonetheless, questions around collective and personal identity - of who and what BERJ is for, and who belongs in and is a part of education - are important to consider.

Questions over identity and belonging are not straightforward but always political in nature. Diverse actors work to configure who and what belongs through struggles over every day disciplinary practices, with publication being an important element of this. Exacting questions about who and what is included, and by implication, who and what is excluded, are essential for encouraging diversity. Indeed, this provokes questions about why certain histories, issues and groups have been studied and prioritized, and others have not.

Here we can learn from the call and movement to decolonise education (Bhambra et al, 2018; Tuck and Yang, 2012) - whether this be in terms of the materialities of educational institutions, the diversity of its researchers, practitioners and students, or the inclusions and exclusions to educational histories and education's wider curricula. To do so requires an expansion of vision and recognition of the power of identity and location, and probes the very foundation of any disciplinary identity. As potential priorities for the future, we want to further encourage conversation that asks questions about education's identity - its past, present and future. And, while cognisant of its challenges, we encourage and would like to open up new and deeper forms of collaborative research and co-production of knowledge that bring together those positioned differently within and in relation to the field of education. Again, manuscripts engaging with these issues are particularly welcomed.

\section{iii. Scale}

The final theme of scale is used to reflect on the focus, scope and reach of educational research; of what educational research looks like and how and where it is done. These are important considerations given the enhanced pressures for certain types of research, funding, and outputs.

Our first point relates to the scale at which we think about the field. In our call for reflections on the field of education, we have been keen to encourage papers that appraise as well as open up and extend debate about what and how things are, or could be, done. More theoretically, historically and philosophically driven and inspired appraisals, as well as critical commentary on the methodologies of educational research, can offer more broad brush (over)views. But they also offer important striking moves for the field of educational research. So while encouraging such papers, we recognise the importance of those that manoeuvre between what can seem like more abstract debate, and the research that takes these ideas and works them through particular topics and case studies at a more local and intimate level.

This leads to the second point, the scale at which we work within the field. The scale at which research happens, at which research questions are developed, data are collected and analysed, all warrant attention. Researchers in many institutional settings are being encouraged to 'scaleup' research; be alert and respond to the international context and in so doing meet the requirements of funding bodies, organisational and institutional targets and priorities. For example, the discussion of and agenda relating to Global Challenges encourages a broadening of our research frame and context. Education weaves through the Global Challenges Research Fund strategy and challenge areas, with a focus on capacity building and partnership https://www.ukri.org/research/global-challenges-research-fund/ It is indeed crucial that educational researchers respond to these challenges and are able to talk and work across national and disciplinary boundaries to collaborate with others on pressing issues which are 
global in scale. However, while recognising this work at a more global scale, we must not forget that education is experienced at the very local and immediate level. Education translates across varying contexts and scales, and encouragement to research at these different levels of analysis is vital.

This editorial is aimed at pointing to a wider set of concerns that are relevant to those working within the field of education and offering a springboard to prompt further conversation about educational research. BERJ should be a meeting place for the wide educational community and for discussion on topics that matter; that matter to the field but that also reach and extend beyond, to consolidate existing research, as well as highlight new areas and priorities for research.

Journals are spaces of privilege, and editors occupy privileged positions. As editors we are faced with the challenge of acting as gatekeepers to the field while seeking to encourage discussion that challenges boundaries, questions identity, and considers scale in the ways we have suggested. This can be a fraught process that requires both difficult decisions and (self-) critical reflection. For example, in our recent call for special issue/ section proposals, we were both encouraged and surprised by the intense interest and large number of submissions. Deciding which proposals ' $f i t$ ' the journal's remit, and could, potentially, progress towards publication, was a task in exercising our responsibilities towards the journal and its readers, as well as potential authors, and special issue/ section editors. As some topics were chosen, others were inevitably discarded. Through this we were informed by a commitment to consolidating and extending existing research, but also charting new developments and mapping new terrains. Journal special issues and sections are a clear mechanism through which to consolidate, but also alter and expand the field of educational research, sharpening our commitment to publishing cutting-edge research and further enabling the vibrancy of the field. So at this half point in our editorship, we wish to extend thanks to the journal's readers, authors, reviewers and editorial board. The success of the journal and these initiatives depends on a vibrant community that is open to, and supportive of, this endeavour of educational research. We encourage authors to submit manuscripts that continue and deepen the conversation about education and its position within research, policy and practice.

\section{References}

Aldridge, D., Biesta, G., Filippakou, O. and Wainwright, E. (2018) Why the nature of educational research should remain contested: A statement from the new editors of the British Educational Research Journal. British Educational Research Journal, 44. 1-4.

Bhambra, G K., Nisancioglu, K. and Gebrial, D. (eds) (2018) Decolonizing the university. Pluto Press, London

Biesta, G., Filippakou, O., Wainwright, E. and Aldridge, D. (2019) Why educational research should not just solve problems, but should cause them as well. British Educational Research Journal, 45, 1-4

Biesta, G., Allan, J., and Edwards, R.G. (eds) (2014) Making a difference in theory: The theory question in education and the education question in theory. London/New York: Routledge.

Gieryn, T. (1999) Cultural Boundaries of Science. Chicago: The University of Chicago Press

Lawn, M. and Furlong, J. (2007) The social organisation of education research in England. European Educational Research Journal 61, 55-70. 
Lawn, M. and Furlong, J. (2009) The disciplines of education in the UK: Between the ghost and the shadow. Oxford Review of Education 35, 541-552.

McCulloch, G. (2012) Introduction: disciplinarity, interdisciplinarity and educational studies - past, present and future, British Journal of Educational Studies, 60, 295-300

Tibble, J.W. (1966) The development of the study of education. In J.W. Tibble (Ed), The study of education London: Routledge and Kegan Paul. (pp. 1-28).

Tuck, E. and Yang, K. W. (2012) Decolonization is not a metaphor. Decolonization: Indigeneity, Education and Society, 1, 1-14.

Whitty, G. and Furlong, J. (eds) (2017) Knowledge and the study of education: An international perspective. Oxford: Symposium Books. 